\title{
Polymeric emulgel carrying Cinnamomum tamala extract: promising delivery system for potential topical applications
}

\author{
Wajeeha Arshad", Haji Muhammad Shoaib Khan*, Naveed Akhtar, \\ Imran Shair Mohammad ${ }^{\oplus 2}$
}

\begin{abstract}
${ }^{1}$ Department of Pharmacy, Faculty of Pharmacy and Alternative Medicines, The Islamia University of Bahawalpur, Bahawalpur, Pakistan, ${ }^{2}$ Department of Pharmaceutics, School of Pharmacy, China Pharmaceutical University, Nanjing, P.R. China
\end{abstract}

\begin{abstract}
Currently, the use of natural compounds obtained from plants tremendously increased due to their promising therapeutic properties. The aim of this study was to formulate a stable emulgel formulation loaded with Cinnamomum tamala (CT) extract. The antioxidant activity of plant extract was determined by DPPH inhibition assay. The extract was successfully loaded into an emulgels using different concentrations of carbopol-940, liquid paraffin, emulsifying agents and preservatives. Preliminary stability study was performed of $17 \mathrm{CT}$ emulgel formulations at accelerated temperature of $50{ }^{\circ} \mathrm{C}$ for 2 -months. Organoleptic evaluation, centrifugation, globule size, $\mathrm{pH}$, electrical conductivity and rheological studies were performed for a period of 90-days at different temperature including $8,25,40$ and $40{ }^{\circ} \mathrm{C} \pm 75 \%$ $\mathrm{RH}$. The CT extract showed promising antioxidant activity of about $81 \%$. On the other hand, the CT loaded emulgel formulation displayed high physical stability at all tested conditions of temperature and time. However, slight decrease in $\mathrm{pH}$ and minimum increase in conductivity was observed at 40 and $40{ }^{\circ} \mathrm{C} \pm 75 \% \mathrm{RH}$. The rheological examination of $\mathrm{CT}$ emulgel indicated the flow index values of all the samples kept at different temperatures were less than 1, demonstrated non-newtonian and pseudo-plastic nature of CT emulgel. Taken together, the CT emulgel formulation has been evinced to be an excellent addition in the field of topical formulations.
\end{abstract}

Keywords: Cinnamomum tomala. Antioxidants. Emulgel. Physicak stability. Non-Newtonian. Pseudoplasticity.

\section{INTRODUCTION}

Due to some critical stability problems with emulsion formulations including creaming, phase inversion, flocculation and coalescence, various efforts have been made to prepare a stable emulsion formulation for therapeutic applications (Mohsin, Akhtar, 2007). Recently, there has been great attention towards the use of innovative polymers with multifarious properties as emulsifying and thickening agents in order to improve the stability of emulsion systems by reducing surface as well as interfacial tension and at the same time enhance the viscosity of the aqueous phase (Gupta et al., 2010). In the presence of gelling agent in the emulsion aqueous phase, it transforms emulsion formulation into an emulgel.

\footnotetext{
*Correspondence: H. M. S. Khan. Department of Pharmacy, Faculty of Pharmacy and Alternative Medicines, The Islamia University of Bahawalpur, Bahawalpur, Pakistan, 63100. Tel: 0092-3311143022. E-mail: shoaib.khan@iub.edu.pk
}

Previously, emulgels topical preparations showed numerous advantageous properties such as, spreadability, emollient and improved thixotropic behavior. On the other hand, these jellified emulsions enable improved shelf-life and represent an attractive appearance, even after months of storage (Stanos, 2007). These promising properties of emulgels made them an excellent candidate for the delivery of both aqueous and oleaginous therapeutic ingredients; therefore, emulgels formulations can be employed for the successful development of stable topical drug delivery system, particularly potent natural topical preparations by loading therapeutic herbal extracts (Bleckmann, Kropke, Schneider, 2006; Shahin et al., 2011).

An antioxidant are capable of preventing or slowing the oxidation of other molecules. Mostly, an antioxidant can provide protection against toxic compounds by trapping free radicals thus terminating the chain reaction. The substances, which protect bio-molecules from free 
radical-mediated cellular injury fall under this category, both in-vitro and in-vivo. Reactive oxygen species (ROS) or Reactive Nitrogen Species (RNS) are largely produced during irradiation by UV light, by X-rays and by gamma rays, in metal-catalyzed reactions, produced by neutrophils and macrophages during inflammation and are by-products of mitochondria-catalyzed electron transport reactions and other mechanisms (Flora, 2009). The ROS at higher concentration are important mediators induce significant damage to cell structures, including lipids, membranes, proteins or nucleic acids (termed oxidative stress). These harmful effects of ROS could be balance by antioxidant agents in addition to antioxidant enzymes. Thus, play a pivotal role to prevent and cure oxidative stress based diseases (Niki, 2010). In this respect, many plants have been proved an important source of naturally occurring antioxidants (Mohammad et al., 2015; Phil et al., 2018) and showed numerous promising therapeutic effects (Hameed et al., 2017; Mohammad, He, Yin, 2018).

Cinnamomum tamala is an evergreen tree (Gunjan, Nautiyal, Nautiyal, 2009) and its leaves have documented antidiarrheal, antidiabetic, cytotoxic, anti-inflammatory and potent antioxidant activities (Akter et al., 2015) due to the presence of phenols, ascorbic acid and carotenoids (Chakraborty, Das, 2010). Owing to these eminent therapeutic properties, its demand is increasing nowadays (Sharma, Nautiyal, 2011). Foreseeing the high antioxidant activity of Cinnamomum tamala leaves extract, here we formulated and characterized a novel emulgel formulation loaded with 4\% Cinnamomum tamala extract for a potent topical preparation.

\section{MATERIAL AND METHODS}

\section{Material}

Liquid paraffin (Merck, Darmstadt, Germany), Span 20 (Sigma, USA), Tween 20 (Sigma, USA), propylene glycol (Merck KGaA Darmstadt, Germany), methyl paraben (Acros Organics, USA), propyl paraben (Acros Organic, USA), Carbopol 940 (Sigma, USA), Ethanol (Merck, Germany), distilled water (Department of pharmacy, IUB, Pakistan), 1,1-diphenyl-2-picrylhydrazyl (Sigma, USA), ascorbic acid (Sigma, USA).

\section{Methods}

\section{Plant material and extraction process}

Leaves of Cinnamomum tamala in dried form were purchased from Bahawalpur district, Punjab, Pakistan. An expert botanist did the authentication of the plant material from University of Karachi, Pakistan (no.CT-01-18). After cleaning the leaves, pulverization was done and homogeneous powder was obtained. For maceration $20 \mathrm{~g}$ Cinnamomum tamala leaves powder was macerated with $150 \mathrm{~mL}$ of $70 \%$ ethanol $(70: 30 \mathrm{v} / \mathrm{v})$ at room temperature, for $72 \mathrm{~h}$. Then filter through muslin cloth layers and Whatman filter paper No. 40, the filtrate then subjected to evaporation under vacuum in a rotary evaporator at $35-40{ }^{\circ} \mathrm{C}$ to get concentrated crude extract $(1 / 3$ of original volume). The concentrated extract was then refrigerated at $-20{ }^{\circ} \mathrm{C}$, in an amber colored closed container, for consequent experiments.
$\underline{\mathbf{A}}$

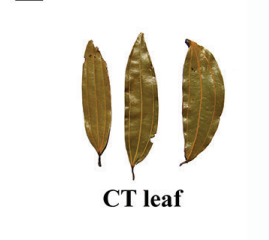

$\underline{\mathbf{C}}$

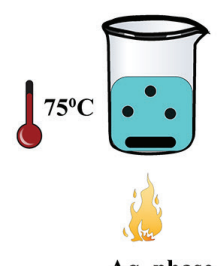

Aq. phase
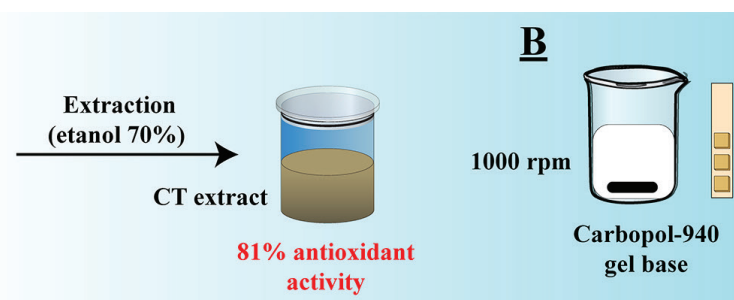

pH 6.5

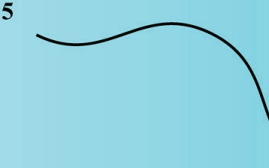

$\underline{D}$

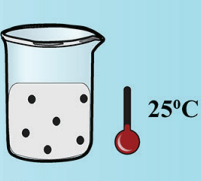

CT emulsion

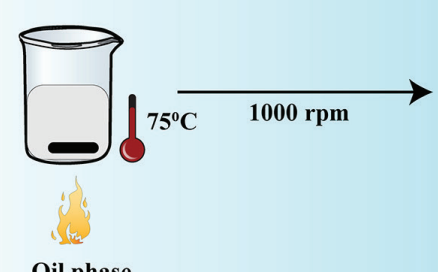

Oil phase

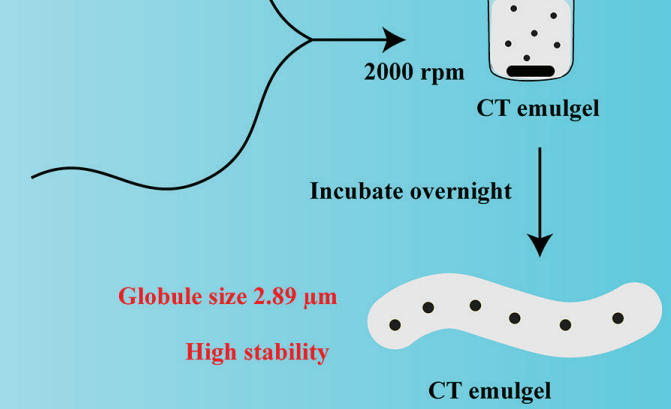

SCHEME 1 - Extraction and preparation of CT emulgel, (A) CT extract was prepared by extraction (70\% ethanol) and showed $81 \%$ antioxidant activity, (B) carbopol-940 gel base was prepared (pH-6.5), (C) CT emulsion was prepared and cooled at room temperature, (D) CT emulgel was fabricated by conjugating carbobol-940 gel base and CT emulsion under continuous stirring at $2000 \mathrm{rpm}$, then incubated overnight to obtain highly stable CT emulgel have globule size upto $3 \mu \mathrm{m}$. 


\section{Antioxidant assay}

The antioxidant activity of $70 \%$ ethanolic extract of CT was performed by previously described method. Briefly, in a 96-well plate, $10 \mu \mathrm{L}$ of CT extract was added with $90 \mu \mathrm{L}$ of $100 \mu \mathrm{M}$ DPPH solution. Then incubated in dark for next $0.5 \mathrm{~h}$, the change in absorbance was measured at $517 \mathrm{~nm}$ by using a microplate reader. In this experiment, the ascorbic acid and methanol was taken as positive and negative control, respectively (Mohsin, Akhtar, 2017). The $\mathrm{DPPH} \%$ inhibition was calculated as follows

$\%$ Inhibition $=[($ Absorbance of control - Absorbance of test)/Absorbance of control] $\times 100$

\section{Preparation of CT emulgel}

\section{Preparation of Carbopol-940 gel}

Carbopol-940 gel base was prepared by dispersing carbopol-940 at $1000 \mathrm{rpm}$ into a glass beaker containing distilled water $(100 \mathrm{~mL})$. After complete dispersion, the tri-ethanolamine was added dropwise. The $\mathrm{pH}$ was carefully monitored at this step and checked after the addition of every drop of tri-ethanolamine, until the $\mathrm{pH}$ of gel base reached 4-6.5 (Khan et al., 2016). Then the gel base was kept overnight to fabricate swelled gel network (Abdullah et al., 2013).

\section{Preparation of CT loaded emulsion}

The aqueous phase of emulsion was prepared by heating tween-20, propylene glycol, propyl paraben, methyl paraben and water upto $75^{\circ} \mathrm{C}$. Similarly, the oil phase was also prepared by heating paraffin oil and span20 at $75^{\circ} \mathrm{C}$. Next, CT extract was added to the aqueous phase. Then oily phase was poured drop by drop to the aqueous phase with constant stirring at $2000 \mathrm{rpm}$ until complete oily phase was added. Then the speed of the system was reduced to $1000 \mathrm{rpm}$ for $5 \mathrm{~min}$ followed by $500 \mathrm{rpm}$ for next $5 \mathrm{~min}$. Finally, the emulsion was cooled at room temperature.

Finally the CT loaded emulsion, was incorporated into previously prepared Carbopol-940 gel base (1:1) (Khullar et al., 2012) under series of stirring speed (2000 rpm for $15 \mathrm{~min}$ then $1000 \mathrm{rpm}$ for $5 \mathrm{~min}$ and finally $500 \mathrm{rpm}$ for $5 \mathrm{~min})$.

\section{Characterization of CT emulgel}

\section{Optimization of CT emulgel test-formulation}

In order to obtained the optimize formulation for consecutive studies, the stability of the prepared CT emulgel test formulations was performed at single factor accelerated temperature conditions (Arshad et al., 2014).

\section{Characterization of optimized CT emulgel}

The characterization and in vitro evaluation of optimized CT emulgel formulation (F-17), was performed on the basis of globule size, organoleptic evaluation, $\mathrm{pH}$, electrical conductivity, phase separation. Furthermore, in vitro occlusivity and rheological aspect was also investigated for 90-days at different time intervals such as, $0,24,7,14,28,60$ and 90-days at different storage conditions in stability chambers $\left(8^{\circ} \mathrm{C}, 25^{\circ} \mathrm{C}, 40^{\circ} \mathrm{C}\right.$ and $\left.40{ }^{\circ} \mathrm{C} \pm 75 \% \mathrm{RH}\right)$.

\section{Determination of globule size}

The microscopic analysis of CT emulgel was performed by using optical microscope (Eclipse E200, Nikon, Japan) equipped with high resolution camera (DCM-35 USB 2.0) and imaging software "Minisee" to observe any changes in globule size. The images of different samples of emulgel formulations after dilution on glass slide were taken under 100-X oil immersion lens. The droplet size of internal phase of sample was analyzed by using software "Digimizer 4.3.1 (Mariakerke, Belgium)".

\section{Organoleptic evaluation}

The organoleptic characteristics including color and phase separation of the samples preserved at $8{ }^{\circ} \mathrm{C}, 25^{\circ} \mathrm{C}$, $40{ }^{\circ} \mathrm{C}$ and $40{ }^{\circ} \mathrm{C} \pm 75 \% \mathrm{RH}$ for 90 -days were evaluated to assess any change in color. While, centrifugal tests for CT-emulgel formulation kept at various storage conditions mentioned above, were carried out at room temperature by placing $2 \mathrm{~g}$ of sample in $15 \mathrm{~mL}$ centrifuge tube and rotating at $5000 \mathrm{rpm}$ for $40 \mathrm{~min}$ (two cycles, each of 20 minutes) in ultra-centrifugation machine (EBA20, Hettich, Germany). Next, the tubes were examined macroscopically for the incidence of any possible phase separation. Phase separation in different samples placed at different storage conditions was noticed for 90-days at specific allocated time intervals.

\section{pH measurements}

The $\mathrm{pH}$ of CT emulgel preserved at different stability conditions was performed with a digital $\mathrm{pH}$ meter in triplicate at predetermined time intervals for a period of 3-months. 


\section{Electrical Conductivity}

The electrical conductivity of CT emulgels stored at different temperatures was assessed by using a digital conductivity-meter for 3 months at specific time periods in triplicate.

\section{Rheological studies of CT emulgel}

To investigate the rheological behavior of the CT emulgel samples at specific time intervals was carried out by using a rotational Rheometer model (DV III ultra, Brookfield, USA) with a cone-plate assembly. A spindle CP-41 was used to measure the rheological characteristics of the samples at $25^{\circ} \mathrm{C}$. Approximately $0.5 \mathrm{~g}$ of each CT emulgel sample was applied to the plate and measurement was taken to construct the rheograms under the gradually increasing shear rate from 10-100 rpm (Mulye, Wadkar, Kondawar, 2013). To observe the changes in rheology, shear rate was maintained for ten seconds before taking measurement. The data was analyzed by using Rheocalc V-2.6 software and rheology, consistency and flow properties of the samples was evaluated by employing Ostwald-de Waele power law,

$$
\tau=\boldsymbol{K} \gamma^{n}
$$

where, $\tau$ is shear stress, $K$ is consistency index (CI), $\gamma$ is shear rate and $n$ is the flow index (FI).

\section{RESULTS AND DISCUSSION}

\section{Antioxidant activity}

As the outermost covering of body, the skin cells are susceptible to oxidative stress due to continuous exposure of ultraviolet light and other various environmental harmful conditions (Mohsin, Akhtar, 2017). In this respect, the antioxidants produce protective effects by breaking chain reactions by interfering with peroxyl radicals having weak O-H or N-H bonds (phenol, napthol, hydroquinone, aromatic amines and aminophenol), break chains by reacting with alkyl radicals (quinones, nitrones, iminoquinones), Hydro-peroxide decomposing (sulphide, phosphide, thiophosphate), metal deactivation (diamines, hydroxyl acids), Cyclic chain termination (aromatic amines, nitroxyl radical, variable valence metal) and synergism of action of several antioxidants (phenol sulphide in which phenolic group reacts with peroxyl radical and sulphide group with hydro peroxide). The antioxidant activity of $70 \%$ ethanolic extract of
Cinnamomum tamala was determined and results showed that exhibited promising DPPH inhibition activity of $81 \%$ as compared to $92 \%$ of control, as shown in Figure 1 panel A. Thus, $70 \%$ ethanolic extract of Cinnamomum tamala displayed potent antioxidant activity and have great potential to be employed for topical preparations. The good antioxidant activity in the edible plants is because of the occurrence of polyphenols, and various other molecules which have protective effect against the damage caused by UV-radiations (Manach et al., 2004). The manifestation of good antioxidant activity recommends CT extract as a potential source for topical formulations to protect against various oxidative stress diseases.

\section{Preparation and optimization of CT emulgel}

Firstly, different test emulsion formulations with altered amounts of paraffin oil, distilled water, surfactants along with $4 \%$ of CT-extract were prepared. Then prepared emulsion were incorporated in two different testing concentrations of carbopol-940 gel, as shown in Table I.

Then, $50 \mathrm{~g}$ of each test emulgel formulations labelled and packed in a glass beaker. Then placed in stability chamber at $50{ }^{\circ} \mathrm{C}$ temperature for a period of 30-days. During this period, the test preparations were investigated by evaluated color and phase separation. After 30-days, four formulations F-8, F-14, F-16 and F-17 found stable at $50{ }^{\circ} \mathrm{C}$, which were again subjected to additional stability testing at different accelerated temperature conditions of $40{ }^{\circ} \mathrm{C}, 40{ }^{\circ} \mathrm{C} \pm 75 \% \mathrm{RH}$ and $50{ }^{\circ} \mathrm{C}$ for another 15 -days. Among the four test formulations F-17 showed complete stability at all storage conditions in term of consistency and physical appearance with globule size of $3.32 \mu \mathrm{m}$, as shown in figure 1 panel B. Thus, an optimized emulgel formulation composition was found to be: paraffin oil $(6.5 \% \mathrm{w} / \mathrm{w})$, span $20(2 \% \mathrm{w} / \mathrm{w})$, Cinnamomum tamala extract $(4 \% \mathrm{w} / \mathrm{w})$, tween $20(1.5 \% \mathrm{w} / \mathrm{w})$, propylene glycol $(5 \% \mathrm{w} / \mathrm{w})$, propyl paraben $(0.03 \% \mathrm{w} / \mathrm{w})$, methyl paraben $(0.01 \% \mathrm{w} / \mathrm{w})$ and distilled water $(80.96 \% \mathrm{w} / \mathrm{w})$. Therefore, F-17 formulation was selected for further physical stability investigations at different storage conditions for extended period of 90-days.

\section{Determination of globule size}

The analysis of emulgel under microscope is an important tool to directly assure the presence of spherical globules of internal phase that shows the formation of emulsion in gel. This verifies the achievement of the method used for the preparation of emulgel (Vasiljevic et al., 2006; Varma et al., 2014). On the 
$\underline{A}$

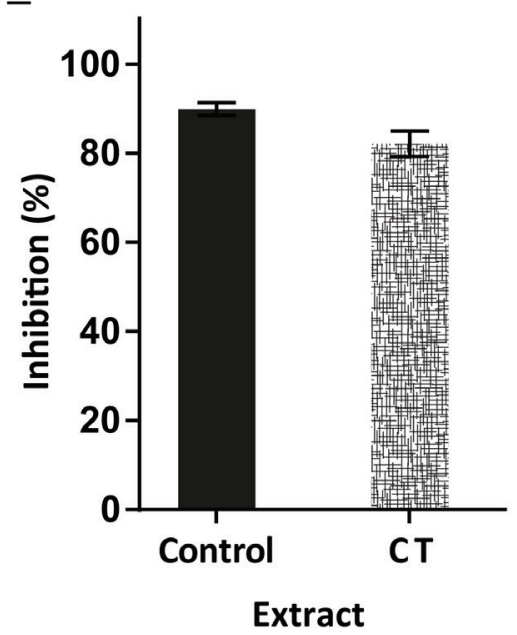

$\underline{B}$

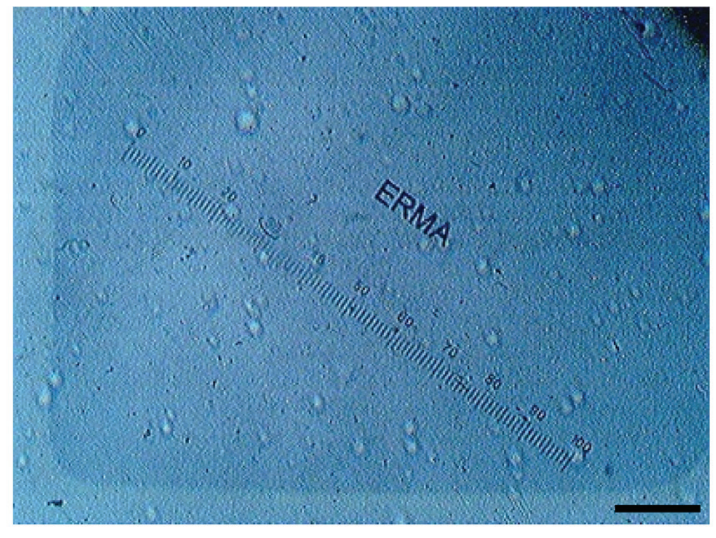

FIGURE 1 - Antioxidant activity of CT emulgel (A), and globule size of freshly prepared CT emulgel (B), scale bar $=100 \mu \mathrm{m}$.

TABLE I - Composition of test formulations of CT emulgel

\begin{tabular}{lccccccccc}
\hline F. Code & $\begin{array}{c}\text { L.P } \\
\text { (g) }\end{array}$ & $\begin{array}{c}\text { Span } \\
(\mathbf{g})\end{array}$ & $\begin{array}{c}\text { Tween } \\
\text { (g) }\end{array}$ & $\begin{array}{c}\text { *Extract } \\
\text { (g) }\end{array}$ & $\begin{array}{c}\text { P.G } \\
\text { (g) }\end{array}$ & $\begin{array}{c}\text { M.P } \\
\text { (g) }\end{array}$ & $\begin{array}{c}\text { P.P } \\
\text { (g) }\end{array}$ & $\begin{array}{c}\text { C 940 } \\
\text { (\%) }\end{array}$ & $\begin{array}{c}\text { D.W } \\
\text { (q.s) }\end{array}$ \\
\hline F1 & 5.5 & 1.0 & 0.5 & 4.0 & 5.0 & 0.03 & 0.01 & 1.0 & 100 \\
F2 & 6.5 & 1.0 & 0.5 & 4.0 & 5.0 & 0.03 & 0.01 & 1.0 & 100 \\
F3 & 7.5 & 1.0 & 0.5 & 4.0 & 5.0 & 0.03 & 0.01 & 1.0 & 100 \\
F4 & 5.5 & 1.5 & 1.0 & 4.0 & 5.0 & 0.03 & 0.01 & 1.0 & 100 \\
F5 & 6.5 & 1.5 & 1.0 & 4.0 & 5.0 & 0.03 & 0.01 & 1.0 & 100 \\
F6 & 7.5 & 1.5 & 1.0 & 4.0 & 5.0 & 0.03 & 0.01 & 1.0 & 100 \\
F7 & 5.5 & 2.0 & 1.5 & 4.0 & 5.0 & 0.03 & 0.01 & 1.0 & 100 \\
F8 & 6.5 & 2.0 & 1.5 & 4.0 & 5.0 & 0.03 & 0.01 & 1.0 & 100 \\
F9 & 7.5 & 2.0 & 1.5 & 4.0 & 5.0 & 0.03 & 0.01 & 1.0 & 100 \\
F10 & 5.5 & 1.0 & 0.5 & 4.0 & 5.0 & 0.03 & 0.01 & 1.5 & 100 \\
F11 & 6.5 & 1.0 & 0.5 & 4.0 & 5.0 & 0.03 & 0.01 & 1.5 & 100 \\
F12 & 7.5 & 1.0 & 0.5 & 4.0 & 5.0 & 0.03 & 0.01 & 1.5 & 100 \\
F13 & 5.5 & 1.5 & 1.0 & 4.0 & 5.0 & 0.03 & 0.01 & 1.5 & 100 \\
F14 & 6.5 & 1.5 & 1.0 & 4.0 & 5.0 & 0.03 & 0.01 & 1.5 & 100 \\
F15 & 7.5 & 1.5 & 1.0 & 4.0 & 5.0 & 0.03 & 0.01 & 1.5 & 100 \\
F16 & 5.5 & 2.0 & 1.5 & 4.0 & 5.0 & 0.03 & 0.01 & 1.5 & 100 \\
F17 & 6.5 & 2.0 & 1.5 & 4.0 & 5.0 & 0.03 & 0.01 & 1.5 & 100 \\
F18 & 7.5 & 2.0 & 1.5 & 4.0 & 5.0 & 0.03 & 0.01 & 1.5 & 100 \\
\hline
\end{tabular}

F. Code $=$ Formulation Code, L.P= Liquid paraffin, $*$ Extract $=$ Cinnamomum tamala leaves extract, $P . G=$ Propylene glycol, M.P= Methyl paraben, P.P=Propyl paraben, C 940= Carbopol 940, D.W= Distilled water, q.s=quantity sufficient to $100 \mathrm{~mL}$

other hand, microscopic analysis, the globule size is a crucial factor to determine stability of globules over time (Arshad, Haji, Akhtar, 2015). Thus, it contributes to the physical stability of the topical preparations. Microscopic examination of emulgel formulation was performed to investigate any change in globule size of formulation.
The figure 2 panel A-E depicts the average globule diameter of formulation at various storage conditions. The mean globule diameter of the freshly formulated CT emulgel was $2.89 \pm 0.12 \mu \mathrm{m}$. A small increase in globule size up to $3.32 \pm 0.38 \mu \mathrm{m}, 3.34 \pm 0.60 \mu \mathrm{m}, 3.38 \pm 0.86 \mu \mathrm{m}$, $3.39 \pm 0.15 \mu \mathrm{m}$ was observed at $8{ }^{\circ} \mathrm{C}, 25^{\circ} \mathrm{C}, 40{ }^{\circ} \mathrm{C}$ and 
$40{ }^{\circ} \mathrm{C} / 75 \% \mathrm{RH}$ at the 90 -day, respectively. The size of the globule appeared to be increasing as function of time. However, this increase in globule size was noted to be a bit slower at low and moderate temperatures in comparison with accelerated conditions. The microstructure examination exhibited spherical globules of small size and no change was detected in shape of globules throughout study period.

The globule size analysis in this study indicated that the emulgel had a small globule size in that range which is desirable for topical products. The extract loaded emulgels exhibited variations in only narrow ranges of globule size which showed that the formulation was fairly stable. On the other hand, the increase in globule size was greater at accelerated conditions (40 ${ }^{\circ} \mathrm{C}$ and $40{ }^{\circ} \mathrm{C} \pm 75 \% \mathrm{RH}$ ), which could be due to the fact that at elevated temperatures, the viscosity of the formulation reduces that may allow the globules to collide and subsequently resulted in increased globule size (Dhanorkar et al., 2002).

\section{Organoleptic evaluation}

The organoleptic characteristics including color and phase separation of the samples preserved at $8{ }^{\circ} \mathrm{C}, 25^{\circ} \mathrm{C}$,
$40{ }^{\circ} \mathrm{C}$ and $40{ }^{\circ} \mathrm{C} \pm 75 \%$ RH for 90 -days were evaluated. Interestingly, no change in color was observed in $\mathrm{CT}$ emulgel F-17 formulation. Furthermore, no sign of phase separation on centrifugation was seen upto 90-days, however a slight phase separation was noticed in samples kept at $40{ }^{\circ} \mathrm{C}$ and $40{ }^{\circ} \mathrm{C} \pm 75 \% \mathrm{RH}$ on 90 -day as shown in Table II. Thus, it was confirmed that emulgel formulation possess good stability under all storage conditions maximally and the extant of slight phase separation was to be dependent on the stressful condition of various temperatures.

The centrifugation is a fast-tracked method to foresee the physical stability in comparison to the lengthy storage studies. The phenomenon is based on the separation of phases under the moderate centrifugal force, depending on the difference in the densities of phases (Masson et al., 2005). Centrifugation causes the destabilization of the formulation resulting from the bumping, collision and coalescence of globules at a swift rate. In preliminary test, if formulation resists phase separation, it will give good clue about the development of stable formulation (Mohsin, Akhtar, 2017). It is obvious from the results that the phase separation may occur, extent of which depends on the holding temperature.

\section{A}

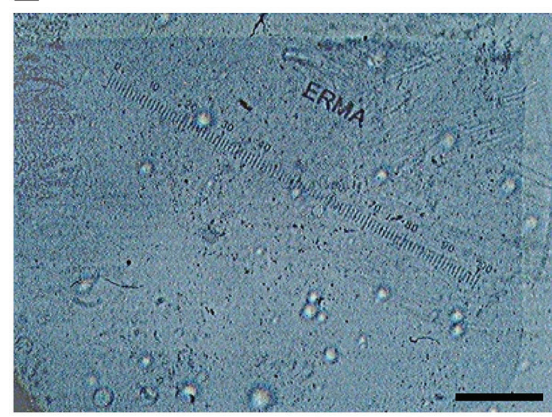

$\underline{\mathbf{D}}$

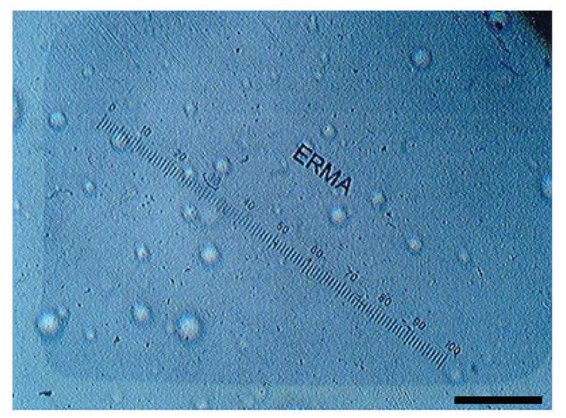

B

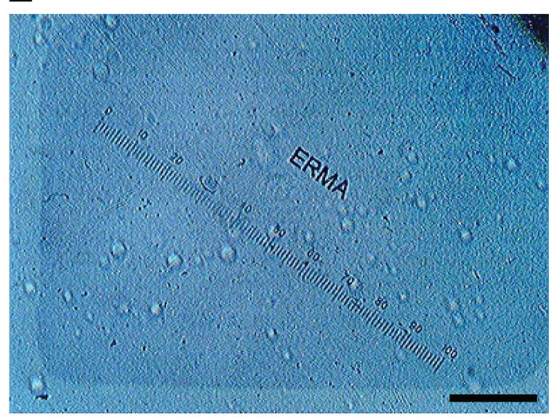

$\underline{E}$

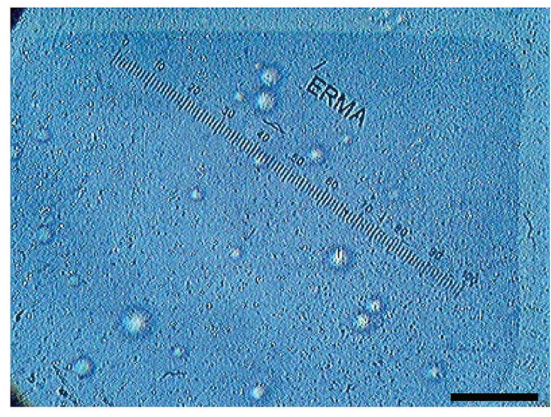

$\underline{\mathbf{C}}$

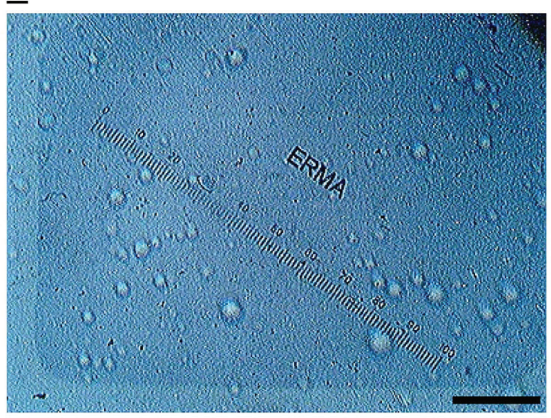

$\underline{F}$

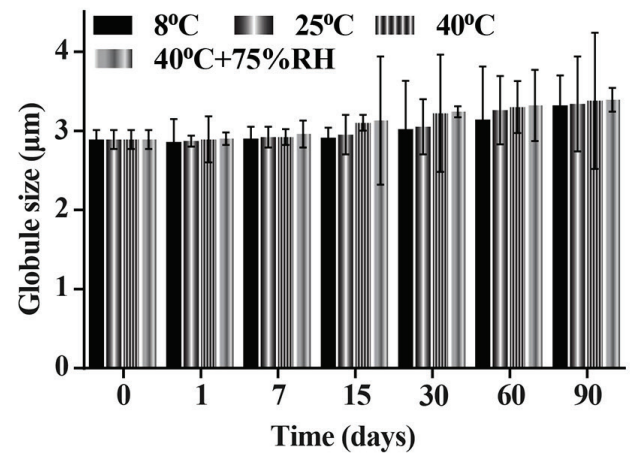

FIGURE 2 - Microscopic images of freshly prepared CT emulgel and samples placed at different storage conditions, (A) freshly prepared CT emulgel, (B) $8{ }^{\circ} \mathrm{C}$ after 90 -days, (C) $25^{\circ} \mathrm{C}$ after 90 -days, (D) $40^{\circ} \mathrm{C}$ after 90 -days, (E) $40{ }^{\circ} \mathrm{C} \pm 75 \% \mathrm{RH}$ after 90 days, $\mathrm{F}$ variation globule size at different storage conditions, scale bar $=100 \mu \mathrm{m}$. 
TABLE II - Organoleptic characteristics of CT emulgel samples placed at different storage conditions

\begin{tabular}{|c|c|c|c|c|c|c|c|c|}
\hline \multirow{2}{*}{$\begin{array}{l}\text { Organoleptic } \\
\text { Characteristics }\end{array}$} & \multirow{2}{*}{ Temperature } & \multicolumn{7}{|c|}{ Time (day) } \\
\hline & & $\mathbf{0}$ & $24 \mathrm{~h}$ & 7 & 14 & 28 & 60 & 90 \\
\hline \multirow{4}{*}{ Color } & $8^{\circ} \mathrm{C}$ & -ve & -ve & -ve & -ve & -ve & -ve & -ve \\
\hline & $25^{\circ} \mathrm{C}$ & -ve & -ve & -ve & -ve & -ve & -ve & -ve \\
\hline & $40^{\circ} \mathrm{C}$ & $-v e$ & -ve & -ve & -ve & -ve & -ve & $-\mathrm{ve}$ \\
\hline & $40^{\circ} \mathrm{C} \pm 75 \% \mathrm{RH}$ & -ve & -ve & -ve & -ve & -ve & -ve & -ve \\
\hline \multirow{4}{*}{ Phase separation } & $8^{\circ} \mathrm{C}$ & $\mathrm{S}$ & $\mathrm{S}$ & $\mathrm{S}$ & $\mathrm{S}$ & $\mathrm{S}$ & $\mathrm{S}$ & $\mathrm{S}$ \\
\hline & $25^{\circ} \mathrm{C}$ & S & S & S & S & S & S & $\mathrm{S}$ \\
\hline & $40^{\circ} \mathrm{C}$ & S & S & S & S & S & S & S \\
\hline & $40^{\circ} \mathrm{C} \pm 75 \% \mathrm{RH}$ & S & S & $\mathrm{S}$ & S & $\mathrm{S}$ & + & ++ \\
\hline
\end{tabular}

-ve: No change, S: stable, +: very slight phase separation, ++: slight phase separation.

\section{pH measurements}

The $\mathrm{pH}$ of topical preparations was found to be a very important parameter regarding their efficiency and stability. Most appropriate formulations for human skin are those which have $\mathrm{pH}$ values closer to skin $\mathrm{pH}$ ( $\mathrm{pH}$ 6.5) so that the risk of irritation to skin may be avoided (Mulye, Wadkar, Kondawar, 2013; Arshad et al., 2014). The $\mathrm{pH}$ of freshly prepared samples of formulations were noticed, and then repeated after various time intervals. Results depicted that $\mathrm{pH}$ of fresh formulation at 0 time was found to be $6.23 \pm 0.01$, which lies within the skin $\mathrm{pH}$ range. No major change in $\mathrm{pH}$ values of formulations at storage conditions of $8^{\circ} \mathrm{C}$ and $25^{\circ} \mathrm{C}$ was observed but slight reduction in $\mathrm{pH}$ of formulation was noticed at $40^{\circ} \mathrm{C}, 40^{\circ} \mathrm{C}$ with $75 \% \mathrm{RH}$, as shown in figure 3 panel $\mathrm{A}$. The trend of $\mathrm{pH}$ values of CT emulgel that were kept at different storage conditions was found to be decreasing but $\mathrm{pH}$ values remained within desired $\mathrm{pH}$ range. This decrease in $\mathrm{pH}$ values with time (3-months) might be due to the oxidation of the paraffin oil, which leads to the production of acidic by-products and aldehydes.

\section{Electrical conductivity determination}

Conductivity is mainly the measure of free ions and water present in the test sample, which can be noticed by determining the consistency of emulgel or emulsions. The electrical conductivity of the freshly prepared CT emulgel was found to be $194.4 \pm 0.95 \mu \mathrm{S} / \mathrm{cm}$, while, at different temperature range and time the electrical conductivity was slightly increased with passage of time. In contrast, at higher temperature ( 40 and $\left.40{ }^{\circ} \mathrm{C} \pm 75 \% \mathrm{RH}\right)$, the increase in conductivity was obvious as compared to the samples placed at 8 and $25^{\circ} \mathrm{C}$ as described in figure 3 panel B.
$\underline{A}$
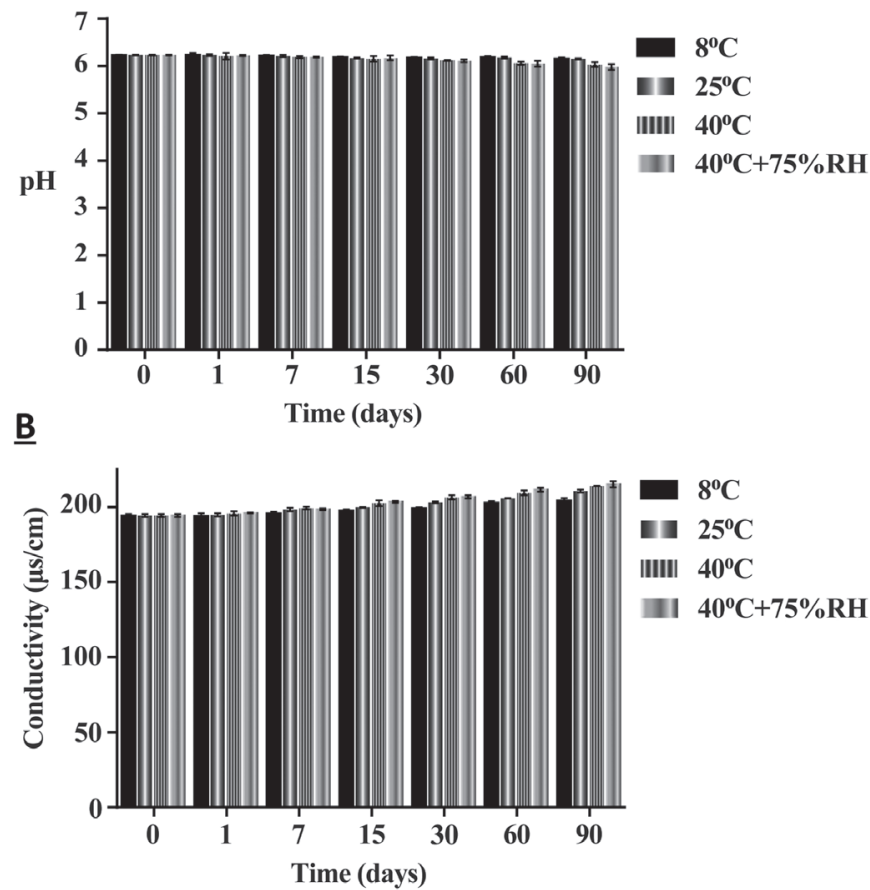

FIGURE 3 - (A) $\mathrm{pH}$ values of $\mathrm{CT}$ emulgel samples kept at $8{ }^{\circ} \mathrm{C}$, $25^{\circ} \mathrm{C}, 40^{\circ} \mathrm{C}$ and $40{ }^{\circ} \mathrm{C} \pm 75 \%$ RH for 90 -days, (B) electrical conductivity of $\mathrm{CT}$ emulgel samples kept $8{ }^{\circ} \mathrm{C}, 25^{\circ} \mathrm{C}, 40^{\circ} \mathrm{C}$ and $40{ }^{\circ} \mathrm{C} \pm 75 \% \mathrm{RH}$ for 90 -days.

During the study period of 90 -days, the conductivity CT emulgel placed at $8,25,40$ and $40{ }^{\circ} \mathrm{C} \pm 75 \% \mathrm{RH}$ were found slightly increased. This increment in conductivity may be due to the clustering of the globules in emulsion and movement or exchange of ions, within the aggregates (Mehta, Gurpeet, Bhasin, 2010). While, slow and steady increase in conductivity values might be associated with the coalescence of aqueous and oily phases (Pays et al., 2002). 


\section{Assessment of rheological behavior of CT emulgels}

The rheological behavior of semisolid topical preparations plays a pivotal role in the assessment of physical stability of topical preparations during shelf life and during their use on skin (Dimambro, Fonseca 2005; Gilbert et al., 2013). The Shear stress produces strain in formulations. That's why by applying shear stress, the material deforms (Waqas et al., 2014) and was due to the progressive disintegration of the internal structure or architecture of the emulgel under increasing shear rate and then its restoration due to Brownian movement of internal phase globules after removal of shear stress (Gaspar, Campos, 2003).

By Ostwald power law the optimized CT emulgel formulation exhibited shear thinning behavior and its flow index and consistency index values at zero time were 0.25 and 5524, respectively. Here, the flow index was observed in the range of $0.25-0.31,0.25-0.34$, $0.25-0.35$ and $0.25-0.39$ at $8,25,40$ and $40{ }^{\circ} \mathrm{C} \pm 75 \% \mathrm{RH}$, respectively, and was manifesting the slight increasing trend of flow index with time. The rheograms of CT emulgel formulation kept at different storage conditions

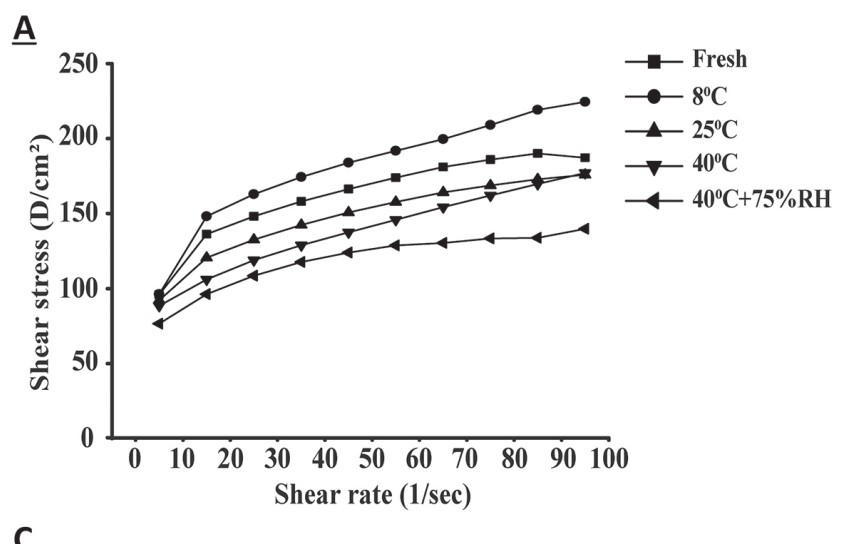

$\underline{\mathbf{C}}$

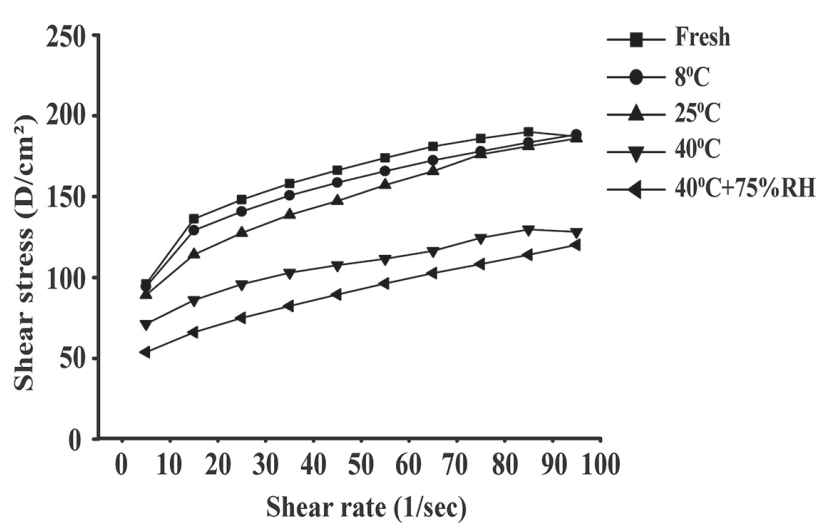

showing shear stress versus shear rate for 90-days are shown in figures 4 panel 1 A-D.

Interestingly, the flow index values of all the samples kept at different temperatures were found less than 1 indicated non-Newtonian and pseudo-plastic nature of $\mathrm{CT}$ emulgel. Moreover, the range of consistency index of CT emulgel was 5524-3869, 5524-2958, 5524-2721, 5524-2993 at 8, 25, 40 and $40{ }^{\circ} \mathrm{C} \pm 75 \% \mathrm{RH}$, respectively, as shown in figure 5 panel $\mathrm{A}$ and $\mathrm{B}$, depicting decrease in consistency index values.

As expected the viscosity of CT emulgel, the viscosity of freshly prepared formulation was $960.30 \mathrm{cP}$ and decreased continuously with the passage of time. The viscosities of sample reduced continuously with increased shear rate, shear stress and temperature. These results were in accordance with the previously report demonstrated that at higher temperature, flow of internal globules through interface was increased and bursting of globules at higher shear stress was responsible in the reduction of viscosity of formulation with time (Mahmood et al., 2013), as shown in Figure 6 panel A-F.

The rheological data of CT emulgel allowed us to characterization CT emulgel by following the changes induced by shear and high temperature to predict their

\section{B}
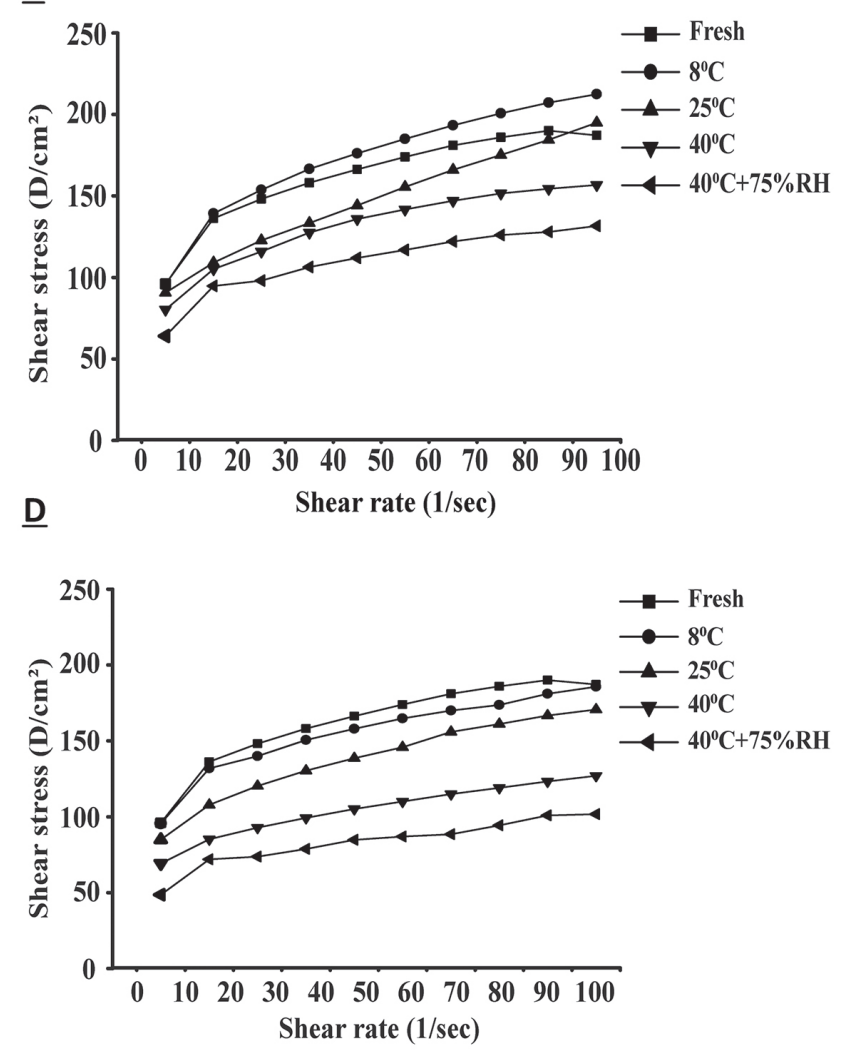

FIGURE 4 - Rheological evaluation of CT emulgel, (A) rheograms of CT emulgel at $8{ }^{\circ} \mathrm{C}$, (B) rheograms of CT emulgel at $25^{\circ} \mathrm{C}$, (C) rheograms of $\mathrm{CT}$ emulgel at $40{ }^{\circ} \mathrm{C}$, (D) rheograms of CT emulgel at $40{ }^{\circ} \mathrm{C}+75 \% \mathrm{RH}$. 
$\underline{A}$

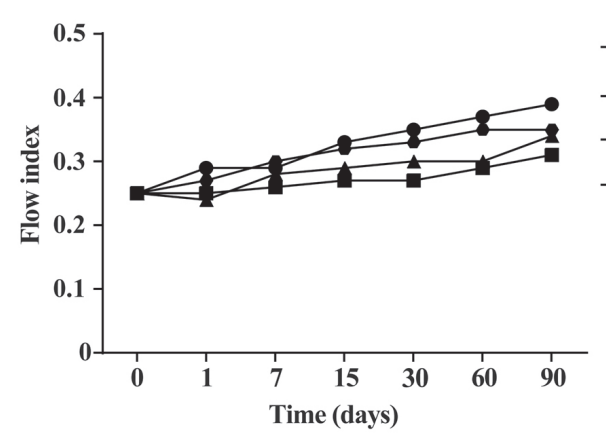

$\underline{B}$

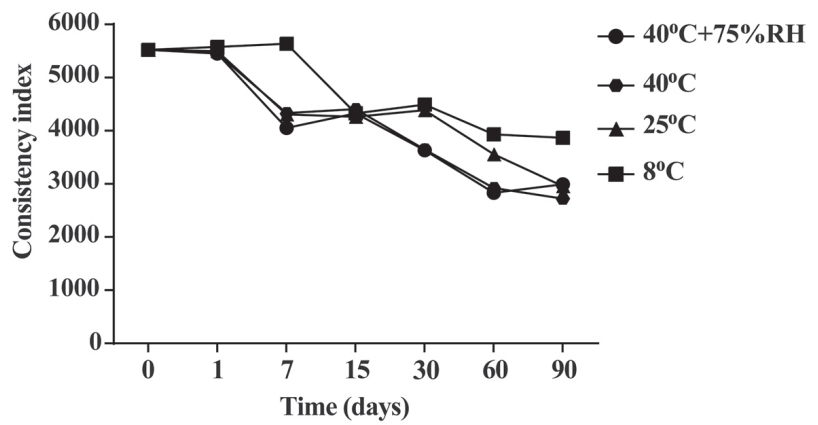

FIGURE 5 - Flow and consistency Index of CT emulgel, (A) flow index values of CT emulgel on 0, 1, 7, 15, 30, 60, and 90-days at $8{ }^{\circ} \mathrm{C}, 25^{\circ} \mathrm{C}, 40^{\circ} \mathrm{C}$ or $40{ }^{\circ} \mathrm{C} \pm 75 \% \mathrm{RH}$, (B) consistency index values of $\mathrm{CT}$ emulgel on $0,1,7,15,30,60$, and 90 -days at $8{ }^{\circ} \mathrm{C}$, $25^{\circ} \mathrm{C}, 40{ }^{\circ} \mathrm{C}$ or $40^{\circ} \mathrm{C} \pm 75 \% \mathrm{RH}$.

$\underline{A}$

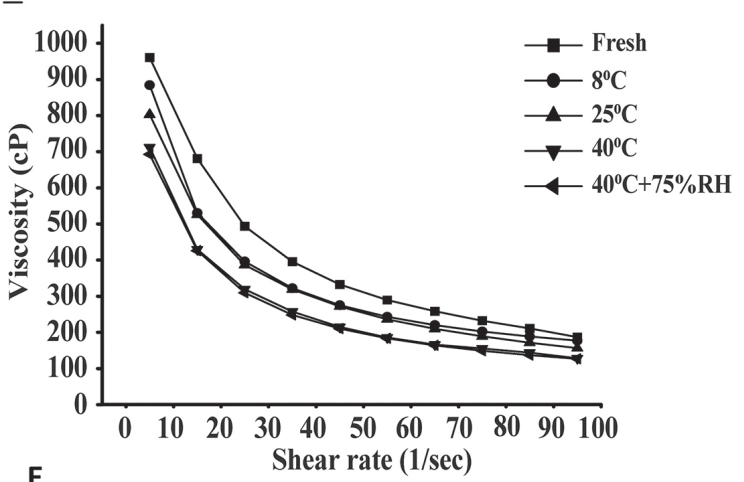

$\underline{E}$

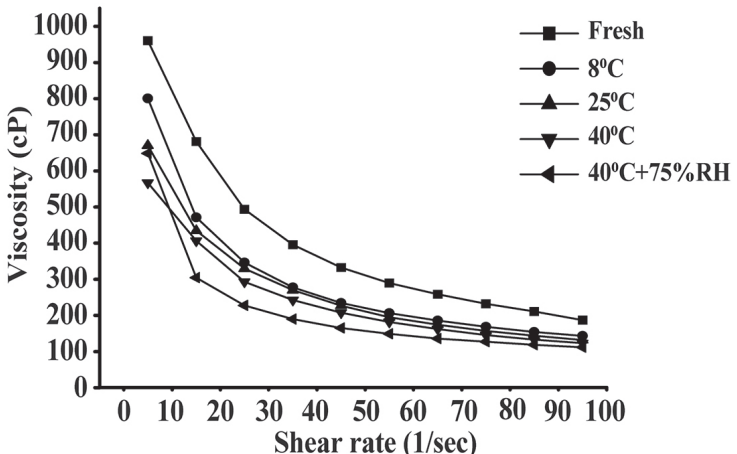

$\underline{B}$
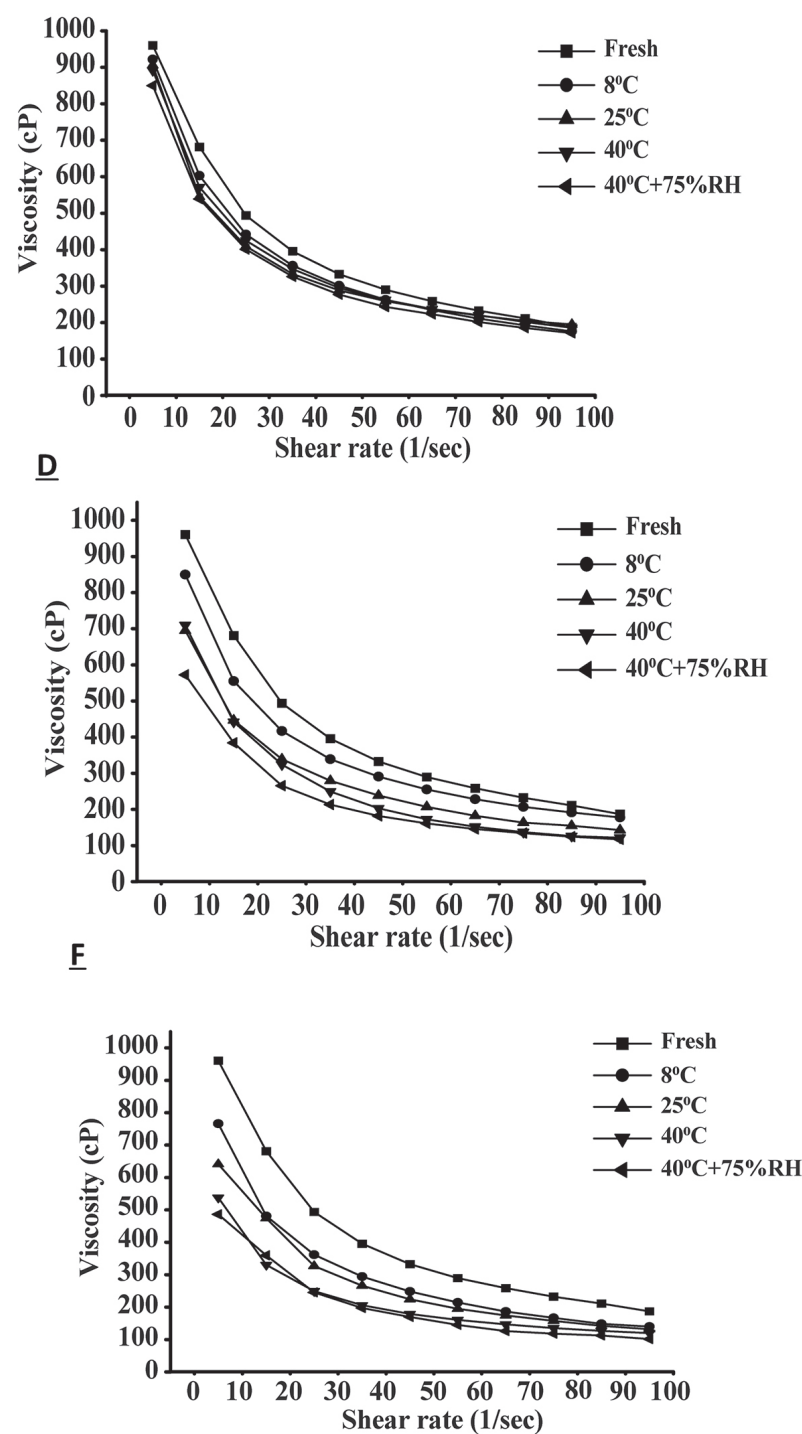

FIGURE 6 - Consistency evaluation of CT emulgel representing rheograms of viscosity v/s shear rate at different temperature and time, (A) viscosity v/s shear rate of CT emulgel at 1-day, (B) viscosity v/s shear rate of CT emulgel at 7-day, (C) viscosity v/s shear rate of CT emulgel at 15-day, (D) viscosity v/s shear rate of CT emulgel at 30-day, (E)viscosity v/s shear rate of CT emulgel at 60-day, and (F) viscosity v/s shear rate of CT emulgel at 90-day. 
stability. Less than 1 flow index values of all the samples placed at different temperatures indicated non-Newtonian and pseudo-plastic nature of CT emulgel. This shear thinning behavior is necessarily important for developing a viscous film over the skin as well as augment the absorption of drug molecules via topical route (Mitsoulis, 2007).

\section{CONCLUSION}

Recently, the attempt to develop novel topical formulation system with exceptional physical stability characteristics seeking more attention. Due to potent antioxidant properties of Cinnamomum tamala extract, the present exploration was intended to fabricate a stable Cinnamomum tamala extract emulgel system with batter stability characteristics. The promising pharmaceutical stability and anticipated physical characteristics manifested by emulgel formulation at series of stability test conditions. Therefore, CT emulgel formulation has been evinced to be an excellent addition in the field of topical preparations. However, its therapeutic potentials must be explored in the field of cosmetic as well as in other topical diseases.

\section{ACKNOWLEDGMENTS}

The authors would like to thanks Higher Education Commission of Pakistan and The Islamia University of Bahawalpur, Pakistn, for providing facilities to finish this research.

\section{AUTHOR CONTRIBUTIONS}

Haji Muhammad Shoaib Khan and Naveed Akhtar designed and approved the experiment, wajeeha arshad performed the experiment and made draft for publication and imran shair mohammad analyzed the data and prepared final draft for publication.

\section{CONFLICT OF INTEREST}

The authors declare no conflict of interest.

\section{REFERENCES}

Abdullah GZ, Abdulkarim MF, Mallikarjun C, Mahdi ES, Basri M, Sattar MA, et al. Carbopol 934, 940 and Ultrez 10 as viscosity modifiers of palm olein esters based nano-scaled emulsion containing ibuprofen. Pak J Pharm Sci. 2013;26(1):7583.
Akter S, Ali MA, Barman RK, Rahman BM, Imam M, Wahed I . In vitro antioxidant and cytotoxic activity of ethanolic extract of Cinnamomum tamala (Tejpat) leaves. Int J Pharm Sci Res. 2015;6(3):532-536.

Arshad AI, Khan HM, Akhtar N, Mustafa R, Aslam I, Mohammad IS. Stability assessment of polysiloxane polyalkyl polyether copolymer based cosmetic emulsion loaded with ananas comosus extract. Lat Am J Pharm. 2014;33(8):1363-70.

Arshad AI, Haji MSK, Akhtar N. Fabrication, preliminary stability evaluation and in-vitro characterization of polysiloxane polyalkyl polyether copolymer-based cosmetic emulsion. Lat Am J Pharm. 2015;34(9):1797-1807.

Bleckmann A, Kröpke R, Schneider G. Preparations of the W/O emulsion type with an increased water content, and comprising cationic polymers. Google Patents. 2006.

Chakraborty U, Das H. Antidiabetic and antioxidant activities of Cinnamomum tamala leaf extracts in Stz-treated diabetic rats. Global J Biotechnol Biochem. 2010;5(1):12-18.

Dhanorkar VT, Gawande RS, Gogte BB, Dorle AK. Development and characterization of rosin-based polymer and its application as a cream base. Int J Cosmet Sci. 2002;53(4):199-208.

Dimambro VM, Fonseca MJ. Assays of physical stability and antioxidant activity of a topical formulation added with different plant extracts. J Pharmaceut Biomed Anal. 2005;37(2):287-295.

Flora SJS. Structural, chemical and biological aspects of antioxidants for strategies against metal and metalloid exposure. Oxid Med Cell Longev. 2009;2(4):191-206.

Gaspar LR, Campos PMBG. Rheological behavior and the SPF of sunscreens. Int J Pharm. 2003;250(1):35-44.

Gilbert L, Picard C, Savary G, Grisel M. Rheological and textural characterization of cosmetic emulsions containing natural and synthetic polymers: relationships between both data. Colloids Surf A Physicochem Eng Asp. 2003;421:150-163.

Gunjan S, Nautiyal BP, Nautiyal AR. Seedling emergence and survival in Cinnamomum tamala under varying microhabitat conditions: conservation implications. Trop Ecol. 2009;50(1):201-209.

Gupta A, Mishra AK, Singh AK, Gupta V, Bansal P. Formulation and evaluation of topical gel of diclofenac sodium using different polymers. Drug Invent Today. 2010;2(5):250-253. 
Hameed A, Ijaz S, Mohammad IS, Muhammad KS, Akhtar N, Khan HMS. Aglycone solanidine and solasodine derivatives: A natural approach towards cancer. Biomed Pharmacother. 2017;94:446-457.

Khan H, Akhtar N, Ali A, Khan HMS, Sohail M, Naeem M, Nawaz Z. Physical and chemical stability analysis of cosmetic multi-ple emulsions loaded with ascorbyl palmitate and sodium ascorbyl phosphate salts. Acta Poloniae Pharm. 2016;73(5):1339-1349.

Khullar R, Kumar D, Seth N, Saini, S. Formulation and evaluation of mefenamic acid emulgel for topical delivery. Saudi Pharm J. 2012;20(1):63-67.

Mahmood T, Akhtar N, Khan BA, Rasul A, Khan HS. Fabrication, physicochemical characterization and preliminary efficacy evaluation of a W/O/W multiple emulsion loaded with 5\% green tea extract. Braz J Pharm. 2013;49(2):341-349.

Manach C, Scalbert A, Morand C, Rémésy C, Jiménez L. Polyphenols: food sources and bioavailability. Am J Clin Nutr. 2004;79(5):727-747.

Masson DS, Morais GG, De Morais JM, De Andrade FF, Dos Santos OD, De Oliveir WP, Rocha Filho PA. Polyhydroxy alcohols and peach oil addition influence on liquid crystal formation and rheological behavior of o/w emulsions. J Disp Sci Technol. 2005;26(4):463-468.

Mehta SK, Gurpeet K, Bhasin KK. Tween-embedded microemulsions-physicochemical and spectroscopic analysis for antitubercular drugs. AAPS Pharm SciTech. 2010;11(1):143153.

Mitsoulis E. Annular extrudate swell of pseudoplastic and viscoplastic fluids. J Non- Newton Fluid Mech. 2007;141(23):138-147.

Mohammad IS, He W, Yin, L. Understanding of human ATP binding cassette superfamily and novel multidrug resistance modulators to overcome MDR. Biomed Pharmacother. 2018;100:335-348.

Mohammad IS, Khan HMS, Arshad, AI, Ijaz H, Banerjee P, Khan AU, Juthi A. In vitro characterization and assessment of cosmetic potentials of w/o emulsion cream containing $2 \%$ prosopis cineraria extract. Acta Pol Pharm Drug Res. 2015;72(6):1233-38.
Mohsin S, Akhtar N. Formulation and stability evaluation of bauhinia variegata extract topical emulsion. Acta Pol Pharm. 2017;74(3):945-954.

Mulye SP, Wadkar KA, Kondawar MS. Formulation development and evaluation of Indomethacin emulgel. Pelagia Res Libr Pharm Sinica. 2013;4(5):31-45.

Niki E. Assessment of antioxidant capacity in vitro and in vivo. Free Radic Biol Med. 2010;49(4):503-515.

Pays K, Giermanska Kahn, Pouligny B, Bibette J, LealCalderon. Double emulsions: how does release occur? J Control Release. 2002;79(1-3):193-205.

Phil L, Naveed M, Mohammad IS, Bo L, Bin D. Chitooligosaccharide: An evaluation of physicochemical and biological properties with the proposition for determination of thermal degradation products. Biomed Pharmacother. 2018;102:438-451.

Shahin M, Hady SA, Hammad M, Mortada N. Optimized formulation for topical administration of clotrimazole using Pemulen polymeric emulsifier. Drug Deve Ind Pharm. 2011;37(5):559-568.

Sharma G, Nautiyal A. Cinnamomum tamala: A valuable tree from Himalayas. J Appl Res Med Aromat Plants. 2011;1(1):1-4.

Stanos SP. Topical agents for the management of musculoskeletal pain. J Pain Symptom Manag. 2007;33(3):342-355.

Varma VNSK, Maheshwari P, Navya M, Reddy SC, Shivakumar H, Gowda D. Calcipotriol delivery into the skin as emulgel for effective permeation. Saudi Pharm J. 2014;22(6):591-599.

Vasiljevic D, Parojcic J, Primorac M, Vuleta G. An investigation into the characteristics and drug release properties of multiple $\mathrm{W} / \mathrm{O} / \mathrm{W}$ emulsion systems containing low concentration of lipophilic polymeric emulsifier. Int J Pharm. 2006;309(12):171-177.

Waqas MK, Naveed A, Jamil QA, Ijaz S, Khan HMS, Murtaza G. Physical stability, rheological analysis and antioxidant study of cetyl dimethicone copolyol based cosmetic water-in-oil emulsions. Lat Am J Pharm. 2014;33(10):1655-1661.

Received for publication on $25^{\text {th }}$ April 2018 Accepted for publication on $12^{\text {th }}$ December 2018 